\title{
Rapid Identification and Drug Susceptibility Testing of Mycobacterium tuberculosis: Standard Operating Procedure for Non-Commercial Assays: Part 1: Microscopic Observation Drug Susceptibility Assay v2.4.12
}

\author{
Sarman Singh ${ }^{1,4}$, Parveen Kumar ${ }^{1}$, Shreya Sharma ${ }^{1}$, Francis Mumbowa ${ }^{2,4}$, \\ Anandi Martin ${ }^{3,4}$, Nicolas Durier ${ }^{4}$
}

'Department of Laboratory Medicine, Division of Clinical Microbiology, All India Institute of Medical Sciences, New Delhi, India, ${ }^{2}$ Medical Microbiology, School of Biomedical Sciences, Makerere University College of Health Sciences, Kampala, Uganda, ${ }^{3}$ Biochemistry and Microbiology, Ghent University, Belgium, ${ }^{4}$ Culture and Drug Susceptibility Testing Subgroup, New Diagnostic Working Group, STOP TB Partnership, Geneva, Switzerland

Address for correspondence: Prof. Sarman Singh, E-mail: sarman_singh@yahoo.com

\section{ABSTRACT}

Multidrug-resistant tuberculosis is an increasing public health concern in many parts of the world, especially in low-income countries, where most cases occur. Traditional mycobacteria culture and drug susceptibility testing (DST) is either time-consuming or expensive and for that reason uptake of these technologies has remained limited in many resource-constrained settings. However, several non-commercial culture and DST methods that do not require sophisticated infrastructure and techniques have been developed. One such method is the microscopic observation drug susceptibility assay (MODS). In this method microcolonies that form in the liquid culture medium after specimen inoculation to drug-free and drug-containing micro-wells are detected by visual observation with a simple inverted microscope. The identification and drug susceptibility results can be obtained in 7-15 days. This standard operating procedure document has been developed through the culture and DST subgroup of the STOP TB Partnership, New Diagnostic Working Group. It is intended for laboratories that would want to use or already using this rapid non-commercial method for culture identification and DST of Mycobacterium tuberculosis, notably in resource-constraint settings in Asia and Africa.

Key words: Tuberculosis, rapid, drug susceptibility testing, Stop-TB, Training

\section{INTRODUCTION}

Scope

his standard operating procedure (SOP) document has been specially compiled for implementation of the non-commercial culture and drug susceptibility testing (DST) methods endorsed by New Diagnostic Working Group (NDWG)-STOP TB Partnership (WHO) for laboratory network

\begin{tabular}{|l|l|}
\hline \multicolumn{2}{|c|}{ Access this article online } \\
\hline Quick Response Code: & \\
\hline & Website: \\
\hline & www.jlponline.org \\
\hline & \\
\hline
\end{tabular}

performing the rapid non-commercial rapid culture identification and DST for Mycobacterium tuberculosis and intended for the use of Tuberculosis (TB) Diagnostic Laboratories, located in various Asian countries. It is also intended as a companion to the TB laboratory training manuals.

This SOP describes the procedure for the microscopic observation drug susceptibility assay (MODS), from the preparation of reagents and decontamination of the biological specimen, to the detection of mycobacterial growth and interpretation of the direct drug susceptibility results. It is a manual liquid mycobacterial culture method utilizing microscopic observation for detection of M. tuberculosis and DST. It can be performed as direct or indirect tests, for rapid screening of patients suspected of having multidrug-resistant tuberculosis (MDR-TB). Using an 
inverted microscope, microcolonies can be detected in a median of 7 days, much earlier than macroscopic colony growth can be seen on solid medium.

As suspensions with viable, infectious bacteria are handled, strict compliance with safety and protection measures is mandatory. The procedure must be carried out in a laboratory meeting the WHO standards for biosafety level 2 with access restricted to authorized personnel only.

\section{Purpose}

The purpose of this SOP is to rapidly provide clinicians with information about the patients suspected to have multidrug resistant (MDR) M. tuberculosis for proper clinical management.

\section{Personnel qualifications}

The test performer should be having a diploma in laboratory technologies and preferably university graduate in biological sciences with sufficient experience.

\section{Medical fitness}

In accordance with national laws and practices, arrangements should be made for appropriate health surveillance of TB laboratory workers:

- Before enrolment in the TB laboratory

- At regular intervals thereafter, annually or bi-annually

- After any biohazard incident

- In case of onset of TB symptoms

All cases of disease or death identified in accordance with national laws and/or practice as resulting from occupational exposure to biological agents shall be notified to the competent authority.

\section{Education and training}

Personnel are required to be knowledgeable of the procedures in this SOP. Documentation of training and familiarization with this SOP can be found in the training file for each employee.

The laboratory staff shall confirm (i.e., documentation in the training file of familiarization with the SOP) that they can properly perform the procedure before commencing work. Education and training must be given on the following topics:

- Potential risks to health (symptoms of TB disease and transmission)
- Precautions to be taken to minimize aerosol formation and prevent exposure

- Hygiene requirements

- Wearing and use of protective equipment and clothing

- Handling of potentially infectious materials

- Laboratory design, including airflow conditions

- Use of biological safety cabinets (BSC) (operation, identification of malfunctions, maintenance)

- Use of autoclaves, incubators (operation, identification of malfunctions, maintenance)

- Prevention of incidents and steps to be taken by workers in the case of incidents (biohazard incidents, chemical, electrical and fire hazards)

- Good laboratory practice and good microbiological techniques

- Organization of work flow and procedures

- Waste management

- Importance of laboratory results for patient management

- Importance of laboratory results for the national TB programme

- Training shall be given before a staff member takes up his/her post

- Repeat training periodically, preferably every year

Bio-safety precautions in tuberculosis laboratory

TB laboratory has all the major facility requirements for handling $M$. tuberculosis safely, and involves minimum risk to the laboratory personnel if they take proper precautions, and employ proper techniques described in these SOPs. Laboratory safety involves all the procedures and methods one needs to follow to minimize the risks of laboratory acquired infections. Use of laboratory is limited to trained TB laboratory personnel.

Biological safety cabinets

- Switch ON the safety cabinets for at least $30 \mathrm{~min}$ before use. Note that the reading on the mini gauge pressure is satisfactory.

- Wear double pair of gloves, every time you work inside the cabinet.

- Biosafety cabinets need to be cleaned with 5\% phenolic or 1\% hypochlorite solution before work.

- Keep disposal bin/vessel with 5\% phenolic or 5\% hypochlorite disinfect inside the cabinet at right side corner.

- Wipes of Gauge-cloth soaked in 5\% phenolic or 5\% hypochlorite, should be readily available inside the cabinet.

- Arrange all un-infected material required towards left side.

Journal of Laboratory Physicians / Jul-Dec 2012 / Vol-4 / Issue-2 
- All the processed samples need to be arranged right side.

- Do not process more than six specimens at a time, inside the cabinet.

- After completion of work, wipe off the surface with $5 \%$ phenolic solution, and discard all wipes in biohazard bags, or in disposal container meant for infectious materials.

- Discard off the outer glove, too, inside the bio-safety cabinet.

- Wipe off inner glove with disinfectant before touching anything else in the laboratory.

\section{Waste disposal and handling}

All infectious waste should be discarded in the bio-safety disposal bin. All infectious solid waste-wipes, swabs, plastic, paper towels, gauze pads, gloves, etc., should be placed inside the double autoclave bags, sealed with autoclave tape and sterilized at $121^{\circ} \mathrm{C}$ for $30 \mathrm{~min}$ in the autoclave.

Liquid waste, in the steel discarding bins, should be disinfected in $5 \%$ phenol for at least $1 \mathrm{~h}$, before sealing the caps and autoclaved at $121^{\circ} \mathrm{C}$ for $30 \mathrm{~min}$.

\section{Accidents and spillages}

\section{i. Spills inside biological safety cabinets}

All workers using the bio-safety cabinets should keep absorbent materials (gauge cloth/adsorbent sheet) and $5 \%$ phenol within the cabinet.

- Alert all people in lab of immediate area of in the event of spill

- Spread 5\% phenol soaked wipe immediately, while the BSC continues to operate. Wait for 15-20 min

- Use paper towels to wipe up the spill, working from the edges into the center

- Decontaminate equipment: Items that are not readily or easily surface decontaminated should be carefully placed into autoclave bags and removed for further treatment (e.g., decontamination by autoclaving)

- Contaminated gloves and clothes (sleeves are most likely to be contaminated); remove and decontaminate the lab coat by autoclaving or soaking in decontaminant

\section{ii. Spills outside containment room in the biological} safety cabinets

Spills on equipment (such as vortex, centrifuge, incubator, refrigerator etc), laboratory benches, walls, or floors:
- Immediately indicate to all personnel working in the lab, and evacuate for $1 \mathrm{~h}$ to allow dissipation of aerosols created by the spill (negative air pressure system would clear the aerosols)

- Leave the BSC operating and cultures inside cabinet

- Leave the containment facility following exit procedures

- Close laboratory doors and post-warning signs to prevent others from entering the laboratory

- Thoroughly wash hands and other apparently contaminated areas with soap and water. Put on clean disposable gloves

- If personal clothing is contaminated, remove all outer clothing and place it in the autoclave or container for autoclaving. Put on clean garments

- Upon returning to the laboratory wear the N95 mask, fresh lab coat and double pair gloves to start decontamination, cover the spill area with paper towels soaked in 5\% Phenol solution or 1:10 dilution of $20 \%$ bleach (freshly prepared), or $70 \%$ ethanol solution (do not pour decontamination solution directly onto the spill in order to avoid additional release of aerosols)

- Let stand for $20 \mathrm{~min}$ then wipe up with paper towels

- Wipe up the spill with the soaked paper towels and place the used towels in an autoclave bag and autoclave

- Place gloves and paper towels in autoclave bag and autoclave

- Spill inside the centrifuge bucket/tube: Always use the aerosol containment cups for centrifuging. Always open the centrifuge buckets inside the bio-safety cabinet. Autoclave the buckets

- Wash hands and other apparently contaminated areas again with soap and water

iii. Don't

- Eating, drinking, smoking, applying cosmetics, use of mobile phones, or applying contact lenses in the TB laboratory

- Do not allow unauthorized personnel to enter the TB laboratory

- Mouth pipetting

- Crowding of lab with material that is not required inside 


\section{PROCEDURE}

\section{Principle}

MODS a liquid culture based test that detects $M$. tuberculosis and assesses isoniazid (INH) and rifampicin (RIF) susceptibility directly from samples. It is a tissue culture plate based assay which uses oleic acid dextrose catalase (OADC) enriched Middlebrook 7H9 liquid medium supplemented with antibiotic mixture polymyxin, amphotericin, nalidixic acid, trimethoprim, azlocillin (PANTA).

The principle of MODS is based on three characteristics:

- M. tuberculosis grows faster in liquid medium than solid medium.

- Characteristic cord formation can be visualized microscopically in liquid medium at any stage in viable cells and this differentiates it from NTM.

- Incorporation of drugs permits rapid and direct DST concomitantly with detection of bacterial growth.

The simplicity of the technique, the greater sensitivity of liquid over solid media culture for TB detection, the specificity of the characteristic growth of M. tuberculosis, the evaluation of drug susceptibility in a short timescale and the low cost of reagents are the major advantages of the method.

Requirements

Sample

- Clinical sample for direct MODS.

- Pure cultures of acid-fast bacilli grown on solid media/ liquid medium, for indirect MODS.

Equipment and materials

- BSC, class II, annually certified

- Inverted light microscope

- Incubator set at $37^{\circ} \mathrm{C}$

- Autoclave

- Weighing balance

- Refrigerator/freezer

- Vortex

- Micropipettes $(1000 \mu \mathrm{l}, 200 \mu \mathrm{l}$, and $20 \mu \mathrm{l})$

Reagents and solutions preparation

- Sodium hydroxide (NaOH) (Merck, MB1M61-321)

- Tri-sodium citrate $\left(\mathrm{Na}_{3} \mathrm{C}_{6} \mathrm{H}_{5} \mathrm{O}_{7} \cdot 2 \mathrm{H}_{2} \mathrm{O}\right)$ (Fisher Scientific, 14005)

- N-acetyl-1-cysteine (NALC) $\left(\mathrm{C}_{5} \mathrm{H}_{9} \mathrm{NO}_{3} \mathrm{~S}\right)$ (Central Drug House, 011011)
- Potassium dihydrogen phosphate $\left(\mathrm{KH}_{2} \mathrm{PO}_{4}\right)$ (Merck, 1048729025)

- Di-sodium hydrogen phosphate anhydrous $\left(\mathrm{Na}_{2} \mathrm{HPO}_{4}\right)$ (Merck, MG7M571666)

- Di-methyl sulfoxide (Sigma, 472301)

- Glycerol Reagent Grade (Merck, 356350)

- Tween-80 (Merck, SI9S590405).

Drugs

- $\quad$ RIF (Sigma, ref. R7382)

- INH (Sigma, ref. I3377).

Media

- Middlebrook 7H9 broth (ref. 271310-500 g-Becton Dickinson) to be supplemented with glycerol, OADC (ref. 211886 - 10× $20 \mathrm{ml}$ - Becton Dickinson) and PANTA (ref. B4345114 BD Diagnostic Systems).

Other consumables

- Sterile micropipette tips

- Sterile microcentrifuge tubes

- Screw cap glass tubes

- Sterile plastic tubes

- 24-well plates

- Storage vials

- Millipore filters, $0.2 \mu \mathrm{m}$ filters

- Parafilm or Zip lock bags

- $50 \mathrm{ml}$ polypropylene centrifuge tubes.

Preparation

$\mathrm{NaOH}-\mathrm{N} A L \mathrm{C}$ solution preparation

$4 \% \mathrm{NaOH}$ and $2.9 \% \mathrm{Na}$ citrate solution with $0.5 \%$ NALC (decontamination/processing solution)

- $4 \%$ Sodium hydroxide

- $2.9 \%$ Sodium citrate dehydrate or $2.6 \%$ sodium citrate anhydrous

- NALC

The sodium hydroxide and sodium citrate may be mixed as given in Table 1, sterilized and stored in sterile screw cap bottle for use. After NALC has been added, the prepared volume of digestant must be used within $24 \mathrm{~h}$, as NALC loses mucolytic activity on standing for long. For preparation of $\mathrm{NaOH}-\mathrm{NALC}$ solution [Table 1].

Preparation of 0.067 M phosphate buffer ( $p H$ 6.8)

A. Disodium phosphate: Dissolve $9.47 \mathrm{~g}$ of anhydrous Journal of Laboratory Physicians / Jul-Dec 2012 / Vol-4 / Issue-2 
$\mathrm{Na}_{2} \cdot \mathrm{HPO}_{4}$ in 11 of distilled water (DW).

B. Mono-potassium phosphate: Dissolve $9.07 \mathrm{~g}$ of $\mathrm{KH}_{2} \mathrm{PO}_{4}$ in 11 of DW.

- Mix $950 \mathrm{ml}$ of solution A with $950 \mathrm{ml}$ of solution $\mathrm{B}$ and stir; keep back $50 \mathrm{ml}$ of each solution to adjust $\mathrm{pH}$ if necessary

- If final buffer requires $\mathrm{pH}$ adjustments, add solution (A) to raise the $\mathrm{pH}$ or solution (B) to lower it

Preparation of Middlebrook 7H9

Middlebrook 7 H 9 broth base

$5.9 \mathrm{~g}$

Glycerol

$3.1 \mathrm{ml}$

Casitone

$1.25 \mathrm{~g}$

Sterile DW

$900 \mathrm{ml}$

- Dissolve $5.9 \mathrm{~g}$ of $7 \mathrm{H} 9$ medium powder in $900 \mathrm{ml}$ of sterile DW containing $3.1 \mathrm{ml}$ of glycerol and $1.25 \mathrm{~g}$ of casitone.

- Mix until completely dissolved, heat if required.

- Cool and divide the sterile medium into $4.5 \mathrm{ml}$ aliquots in sterile screw capped glass tubes for sample preparation and internal controls. Also aliquot $10.8 \mathrm{ml}$ in sterile screw capped glass tubes for antibiotic solutions.

- Autoclave at $121^{\circ} \mathrm{C}$ for 20 min*

- Incubate at $37^{\circ} \mathrm{C}$ for $48 \mathrm{~h}$ to verify sterility (lack of turbidity).

- Store at $2-8^{\circ} \mathrm{C}$ with cap tightly closed for up to 1 month. (Note: Each sputum sample and internal controls require one tube containing $4.5 \mathrm{ml}$ of $7 \mathrm{H} 9$ medium.)

Final 7H9-OADC and 7H9-OADC-PANTA medium preparation

\section{i. 7H9-OADC}

- OADC: Enrichment supplement (oleic acid, albumin, dextrose, and catalase): Commercial preparation comes ready for use. OADC should be used at $10 \%$ in $7 \mathrm{H} 9$ medium.

- *You can add the OADC after autoclave of the 7H9 medium and cooling down. Add $100 \mathrm{ml}$ OADC to $900 \mathrm{ml}$ of $7 \mathrm{H} 9$ medium

\begin{tabular}{|c|c|c|c|}
\hline \multirow{2}{*}{$\begin{array}{l}\text { Volume of } \\
\text { digestant needed }\end{array}$} & \multicolumn{2}{|c|}{ Mix indicated amounts $(\mathrm{ml})$ of } & \multirow{2}{*}{$\begin{array}{l}\text { Add NALC } \\
\text { (g) }\end{array}$} \\
\hline & $4 \% \mathrm{NaOH}$ & $2.9 \% \mathrm{Na}$ citrate $\cdot 2 \mathrm{H}_{2} \mathrm{O}$ & \\
\hline 50 & 25 & 25 & 0.25 \\
\hline 100 & 50 & 50 & 0.50 \\
\hline 200 & 100 & 100 & 1.00 \\
\hline 500 & 250 & 250 & 2.50 \\
\hline 1000 & 500 & 500 & 5.00 \\
\hline
\end{tabular}

Journal of Laboratory Physicians / Jul-Dec 2012 / Vol-4 / Issue-2 ii. 7H9-OADC-PANTA

- PANTA: Antibiotic supplement used to minimize contamination of MODS culture by oral flora micro-organisms not killed during the decontamination process. The BBL MGIT PANTA vial contains a lyophilized mixture of antimicrobial agents

- Reconstitute a lyophilized vial of BBL MGIT PANTA with $3 \mathrm{ml}$ of sterile DW [Table 2]. Final media preparation should only be performed on the day of using 7H9 medium, OADC and PANTA

Set out

- For every sample: 1 Tube with $4.5 \mathrm{ml} 7 \mathrm{H} 9$ medium +0.5 ml OADC for every sample/or $5 \mathrm{ml} 7 \mathrm{H} 9$-OADC already prepared [Figure 1]

- For the medium control (MC) column: 1 Tube with $4.5 \mathrm{ml} 7 \mathrm{H} 9$ medium for every plate $+0.5 \mathrm{ml}$ OADC/ or $5 \mathrm{ml} 7 \mathrm{H} 9-\mathrm{OADC}$ already prepared

- For the quality control (QC): 2 Tubes with $4.5 \mathrm{ml} 7 \mathrm{H} 9$ medium $+0.5 \mathrm{ml} \mathrm{OADC/or} 5 \mathrm{ml}$ 7H9-OADC already prepared ( 1 for $\mathrm{H}_{37} \mathrm{Rv}$ and 1 for MDR strain)

- For drug solution preparation - 2 tubes/sterile

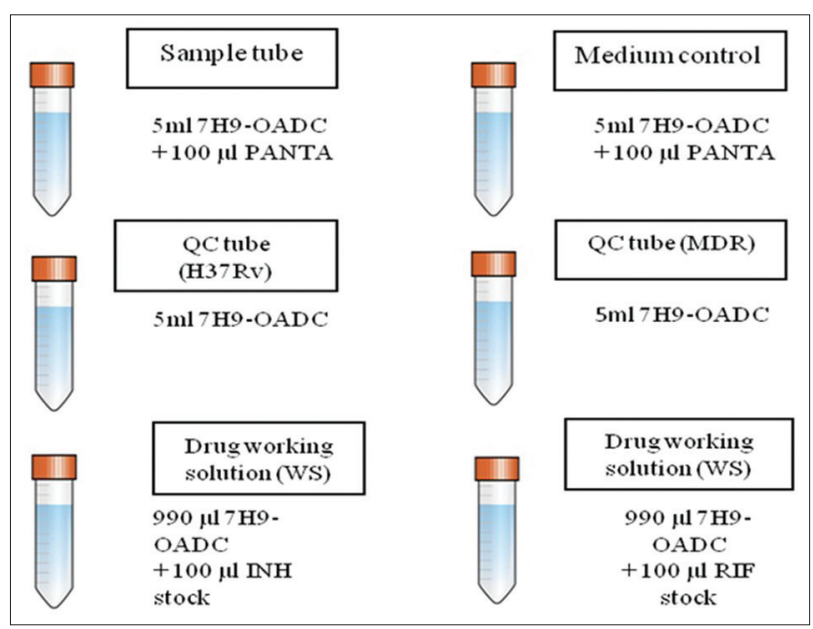

Figure 1: Preparation of medium tubes

Table 2: Polymyxin, amphotericin, nalidixic acid, trimethoprim, azlocillin concentration after reconstitution

\begin{tabular}{lccc} 
Antibiotics & $\begin{array}{c}\text { Formulation } \\
\text { per vial }\end{array}$ & $\begin{array}{c}\text { Concentration } \\
\text { per ml after } \\
\text { reconstitution with } \\
3 \mathrm{ml} \text { sterile DW }\end{array}$ & $\begin{array}{c}\text { Final concentration } \\
\text { in well with sample } \\
\text { and 7H9-OADC } \\
\text { medium }\end{array}$ \\
\hline Polymyxin B & 6000 units & $2000 / \mathrm{ml}$ & $40 \mathrm{units} / \mathrm{ml}$ \\
Amphotericin & $600 \mu \mathrm{g}$ & $200 / \mathrm{ml}$ & $4 \mu \mathrm{g} / \mathrm{ml}$ \\
Nalidixic acid & $2400 \mu \mathrm{g}$ & $800 / \mathrm{ml}$ & $16 \mu \mathrm{g} / \mathrm{ml}$ \\
Trimethoprim & $600 \mu \mathrm{g}$ & $200 / \mathrm{ml}$ & $4 \mu \mathrm{g} / \mathrm{ml}$ \\
Azlocillin & $600 \mu \mathrm{g}$ & $200 / \mathrm{ml}$ & $4 \mu \mathrm{g} / \mathrm{ml}$ \\
\hline
\end{tabular}

DW: Distilled water, OADC: Oleic acid dextrose catalase 
micro centrifuge tube (MCT's) with $990 \mu \mathrm{l}$ 7H9-OADC [Table 3].

- Reconstitute PANTA in $3 \mathrm{ml}$ sterile DW and add $0.1 \mathrm{ml}$ to each sample tube and to the MC tubes $(7 \mathrm{H} 9$-OADC-PANTA: Total volume $=5.1 \mathrm{ml})$.

The final volume of 7H9-OADC and 7H9-OADC-PANTA required will vary according to the number of plates being set-up. (Note: Complete medium 7H9-OADC-PANTA is used for samples and MCs. Use 7H9-OADC without PANTA for QCs and for antibiotic solution preparation.)

Preparation of drug stock and dilution

\section{For preparation of drug stock and drug dilutions}

- Take $990 \mu \mathrm{l}$ of 7H9-OADC in each of the two micro-centrifuge tubes (MCT-1 and MCT-2)

- Add $10 \mu \mathrm{l}$ of INH stock $(0.4 \mathrm{mg} / \mathrm{ml})$ solution to MCT-1 (total volume $1000 \mu \mathrm{l}$ ); mix well. This gives working concentration $(4 \mu \mathrm{g} / \mathrm{ml})$ of INH.

- Add $10 \mu \mathrm{l}$ on RIF stock $(1 \mathrm{mg} / \mathrm{ml})$ solution to MCT-2 (total volume $1000 \mu \mathrm{l}$ ); mix well. This gives working concentration $(10 \mu \mathrm{g} / \mathrm{ml})$ of RIF.

- The tubes are ready for further use [Tables 3 and 4].

Test procedure

\section{Quality control}

Well characterized TB strains: One fully susceptible strain $\left(\mathrm{H}_{37} \mathrm{Rv}\right.$ standard strain) and one MDR strain (if possible) are run as QC. For each batch of MODS plate being set-up 1 batch of QC is run. If the controls do not show the expected pattern, the results of samples plated on that day are not valid.

\section{i. Requirements}

- Susceptible control strain

- MDR control strain

- 7H9-OADC, $5 \mathrm{ml}$

- $10 \%$ sterile Tween $80,40 \mu \mathrm{l}$

- Sterile DW, $10 \mathrm{ml}$

\section{ii. Procedure}

- Mix $10 \mathrm{ml}$ sterile DW and $40 \mu \mathrm{l}$ of $10 \%$ sterile
Tween 80 in a sterile tube (final Tween 80 concentration $=0.04 \%$ )

- Using a sterile loop, harvest several colonies of mycobacteria and place in a sterile tube containing $100 \mu \mathrm{l}$ water-Tween 80 solution and sterile glass beads (do not scrape the medium)

- Cap tube tightly and vortex for 2 - 3 min; (till there are no visible clumps)

- Let it stand for $5 \mathrm{~min}$

- Open tube and add $3 \mathrm{ml}$ of water-Tween 80; cap tightly and vortex again for $20 \mathrm{~s}$ (till suspension has uniform turbidity). Let it stand for $30 \mathrm{~min}$

- Transfer the supernatant to another sterile tube using a pipette

- Adjust turbidity to McFarland Scale 1 (approximately $3 \times 10^{8} \mathrm{CFU} / \mathrm{ml}$ ) with $0.04 \%$ water-Tween 80 solution

- The growth suspension can be used up to 4 weeks (keep at $2-8^{\circ} \mathrm{C}$ )

\section{iii. Preparation of inoculum}

- Mix $5 \mu$ of each McFarland 1 (McF 1) control strain suspension with $5 \mathrm{ml}$ of $7 \mathrm{H} 9-\mathrm{OADC}$ medium. This is the QC suspension ready for plating. The culture suspension for both susceptible strain and MDR strains is prepared separately for plating, as shown in Figure 2

\section{Indirect MODS from culture medium}

Pure culture of acid-fast bacilli grown on solid medium is used for indirect MODS. Confirm the growth as M. tuberculosis using MPT-64, PNB or any other standard methods being practiced in the local laboratory.

\section{i. Requirements}

- 7H9-OADC-PANTA, $5 \mathrm{ml}$

- $10 \%$ sterile Tween $80,40 \mu \mathrm{l}$

\section{ii. Procedure}

- Mix $10 \mathrm{ml}$ sterile DW and $40 \mu \mathrm{l}$ of $10 \%$ sterile Tween 80 in a sterile tube (final Tween 80 concentration $=0.04 \%$ )

- Using a sterile loop, harvest several colonies of Mycobacteria and place in a sterile tube containing

\begin{tabular}{|c|c|c|c|c|c|}
\hline \multirow{2}{*}{$\begin{array}{l}\text { Drugs } \\
\text { Conc. of drug } \\
\text { stock }(\mu \mathrm{g} / \mathrm{ml})\end{array}$} & \multicolumn{3}{|c|}{ Working solution } & \multicolumn{2}{|c|}{ For $1 \mathrm{ml}$ culture suspension/medium } \\
\hline & $\begin{array}{c}\text { Volume of } \\
\text { drug stock }(\mu \mathrm{l})\end{array}$ & $\begin{array}{c}\text { Volume of } \\
7 \mathrm{Hg}-\mathrm{OADC}(\mu \mathrm{l})\end{array}$ & $\begin{array}{c}\text { Conc. of working } \\
\text { solution }(\mu \mathrm{g} / \mathrm{ml})(1: 100)\end{array}$ & $\begin{array}{l}\text { Volume of working } \\
\text { solution }(\mu \mathrm{l})\end{array}$ & $\begin{array}{l}\text { Final conc. in medium } \\
(\mu \mathrm{g} / \mathrm{ml})(1: 1000)\end{array}$ \\
\hline $\mathrm{INH}(400)$ & 10 & 990 & 4 & 100 & 0.4 \\
\hline $\operatorname{RIF}(1000)$ & 10 & 990 & 10 & 100 & 1 \\
\hline
\end{tabular}

Note: The total amount prepared will depend on the number of samples/cultures to be plated. Each sample and medium control requires $100 \mu$ l of each drug working solution. An additional $200 \mu \mathrm{l}$ is required for each QC strain. INH: Isoniazid, RIF: Rifampicin, OADC: Oleic acid dextrose catalase, Conc.: Concentration 


\begin{tabular}{lccc}
\hline Table & 4: Preparation & of drug stock & \\
\hline Drugs & $\begin{array}{c}\text { Stock } \\
\text { concentration } \\
(\mu \mathrm{g} / \mathrm{ml})\end{array}$ & Stock prepared in & $\begin{array}{c}\text { Critical } \\
\text { concentration } \\
(\mu \mathrm{g} / \mathrm{ml})\end{array}$ \\
\hline $\mathrm{INH}$ & 400 & Sterile distilled water & 0.4 \\
$\mathrm{RIF}$ & 1000 & $\begin{array}{l}\text { DMSO+sterile } \\
\text { distilled water (1:1) }\end{array}$ & 1 \\
\hline
\end{tabular}

Note: Prepare drugs in required volume and filter with $0.2 \mu \mathrm{m}$ syringe filter. Store as $20 \mu \mathrm{l}$ aliquots in sterile microcentrifuge tubes, at $-20^{\circ} \mathrm{C}$, for up to 6 months. Calculate the weight of drug necessary according to the potency using the following formula: Concentration required $(\mu \mathrm{g} / \mathrm{ml}) /$ Potency $(\mathrm{mg} / \mathrm{g}) \times$ total volume $(\mathrm{ml})=$ milligrams to weight. INH: Isoniazid, di-methyl sulfoxide (DMSO)

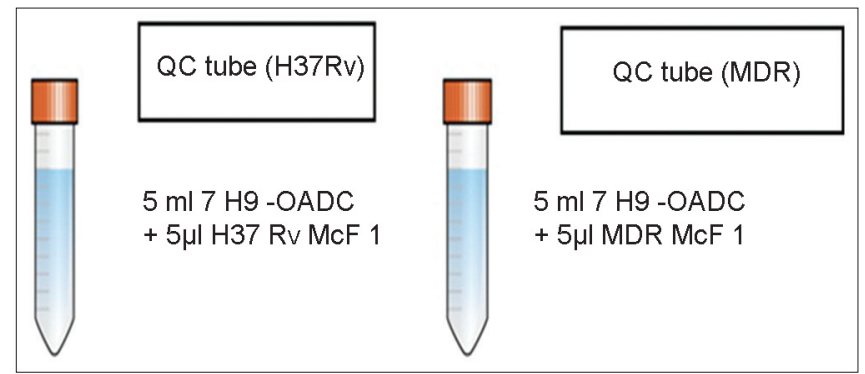

Figure 2: Preparation of inoculum tubes for direct microscopic observation drug susceptibility assay

\begin{tabular}{|c|c|}
\hline QC tube (H37 Rv) & QC tube (MDR) \\
\hline $\begin{array}{c}5 \mathrm{ml} 7 \mathrm{Hg}- \\
\text { OADC }\end{array}$ & $\begin{array}{c}5 \mathrm{ml} 7 \mathrm{H9}- \\
\text { OADC }\end{array}$ \\
\hline $\begin{array}{c}+5 \mu \mathrm{l} \mathrm{H} 37 \mathrm{Rv} \\
\mathrm{McF} 1\end{array}$ & $\begin{array}{c}+5 \mu \mathrm{MDDR} \\
\mathrm{McF} 1\end{array}$ \\
\hline
\end{tabular}

Figure 3: Preparation of inoculum tubes for indirect microscopic observation drug susceptibility assay

$100 \mu \mathrm{l}$ water-Tween 80 solution and sterile glass beads (do not scrape the medium)

- Cap tube tightly and vortex for 2-3 min; (till there are no visible clumps)

- Let it stand for $5 \mathrm{~min}$

- Open tube and add $3 \mathrm{ml}$ of water-Tween 80; cap tightly and vortex again for $20 \mathrm{~s}$ (till suspension has uniform turbidity). Let it stand for $30 \mathrm{~min}$

- Transfer the supernatant to another sterile tube using a pipette

- Adjust turbidity to McFarland Scale 1 (approximately $3 \times 10^{8} \mathrm{CFU} / \mathrm{ml}$ ) with $0.04 \%$ water-Tween 80 solution. (Note: Preparation of $\mathrm{McF} 1$ suspension involves manipulation of concentrated suspensions of mycobacteria and should only be carried out in a BSC)

\section{iii. Preparation of inoculum}

- Mix $5 \mu \mathrm{l}$ of each McF 1 growth suspension with $5 \mathrm{ml}$ of $7 \mathrm{H} 9$-OADC-PANTA medium. This is the final culture suspension ready for plating, as shown in Figure 3.

\section{For direct MODS from clinical sample}

Clinical sample is used. Sample decontamination is must to avoid bacterial/fungal growth in plate being set-up. Decontamination is carried out using the sodium hydroxide$\mathrm{N}$-acetyl-1-cysteine ( $\mathrm{NaOH}-\mathrm{NALC})$. NALC is a mucolytic agent; it must be added to the sterile $\mathrm{NaOH}-\mathrm{Na}$ citrate solution on the day of use, as activity wanes, if stored for long. The sodium citrate in the $\mathrm{NaOH}$ solution prevents heavy metal ions that may be present from deactivating the NALC.

\section{i. Samples not requiring decontamination}

The following specimens usually do not need decontamination when aseptically collected into sterile containers:

- Spinal or other internal body fluids but should be collected aseptically

- Bone marrow aspirate if collected aseptically

- Pus from closed cold abscesses such as fine needle aspiration cytology (FNAC) material

- Surgically resected specimens (excluding autopsy material)

- Material obtained from pleural, liver and lymph nodes as well as biopsies (if not fistulised).

ii. Requirements for one sample

- $\mathrm{NaOH}-\mathrm{NALC}$ solution, 3-5 ml

- $\quad 0.067 \mathrm{M}$ phosphate buffer (pH 6.8), $45 \mathrm{ml}$

- 7H9-OADC-PANTA, $5.1 \mathrm{ml}$

iii. Procedure for decontamination of sputum using $\mathrm{N}$-acetyl-1-cysteine sodium hydroxide $(\mathrm{NaOH}-$ NALC): Modified Petroff's Method

The mucolytic agent, NALC is used for rapid digestion of sputum this enables the decontaminating agents like $\mathrm{NaOH}$, to be used at a lower concentration (in sputum).

- Transfer a maximum volume of 3-5 $\mathrm{ml}$ of specimen to a sterile $50 \mathrm{ml}$ centrifuge tube (aerosol free and graduated).

- Add equal volume of NALC-NaOH-Na citrate solution aseptically.

- Mix the control for approx. $20 \mathrm{~s}$ on vortex mixture. Be sure to invert the tube so that NALC $-\mathrm{NaOH}$ comes in contact with the entire surface of the tube.

- Allow the mixture to stand at room temperature 
for $15 \mathrm{~min}$ to decontaminate the specimen with occasional gentle shaking.

- Neutralize the mixture by adding sterile phosphate buffer ( $\mathrm{pH}$ 6.8) up to the $50 \mathrm{ml}$ in the tube and recap it.

- Centrifuge the tube at $3000 \mathrm{~g}$ for $15 \mathrm{~min}$.

- Decant the supernatant.

Sputum $\rightarrow$ NAOH/NALC decontamination $\rightarrow$ re-suspend the pellet in $2 \mathrm{ml} 7 \mathrm{H} 9-O A D C-P A N T A$ ( $900 \mu \mathrm{l}$ will be plated).

\section{iv. Inoculum preparation}

Using 7H9-OADC-PANTA (from the tube containing $5.1 \mathrm{ml}$ ), re-suspend the sample pellet in a total volume of $2 \mathrm{ml}$ in the centrifuge tube with a Pasteur pipette; mix well.

- Remove $1 \mathrm{ml}$ of sample suspension and store in a storage vial at $2-8^{\circ} \mathrm{C}$ as a backup.

- Add the remaining $1 \mathrm{ml}$ of sample suspension to the tube with the remaining 7H9-OADC-PANTA; mix well. This is the final sample suspension ready for plating.

\section{Medium control}

These are the wells with 7H9-OADC-PANTA culture medium but without sample and these are run on every plate. If any mycobacterial colonies are observed in any well, it indicates cross-contamination.

The entire plate should be discarded and backup samples reprocessed, if available, or new samples requested. Prepare $5.1 \mathrm{ml}$ of $7 \mathrm{H} 9-\mathrm{OADC}$-PANTA. This is the final solution ready for plating.

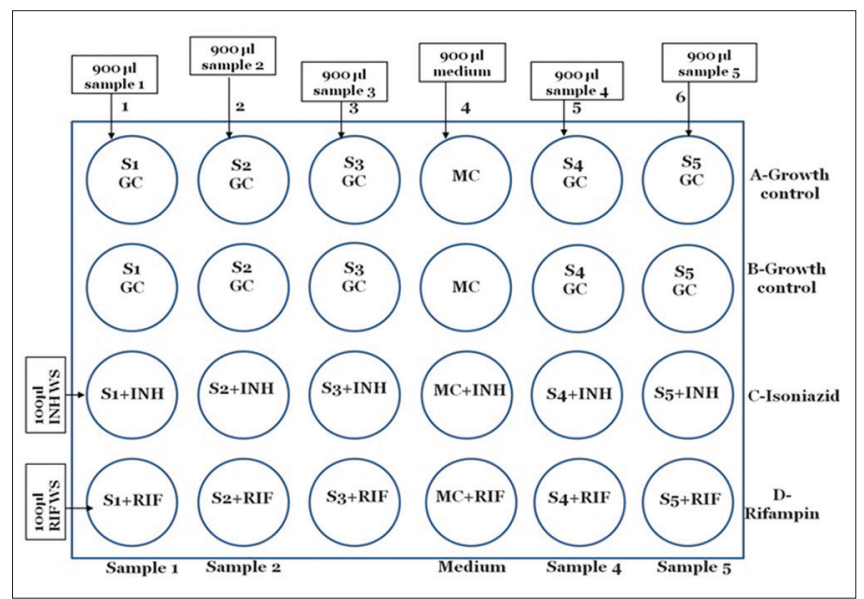

Figure 4: Setting up of microscopic observation drug susceptibility assay plate for sample/culture
MODS method-Setting up the plate

\section{For sample/culture}

- Take a 24 well plate (for upto five samples).

- Mark the wells on plate: Growth control (GC), MC, INH, RIF, as shown in [Figure 4].

- Dispense $900 \mu \mathrm{l}$ of culture/sample suspension in all 4 wells of column 1 to 6 sequentially, except column 4 .

- Dispense $900 \mu \mathrm{l}$ of MC in all 4 wells of column 4.

- Dispense $100 \mu \mathrm{l}$ of working solution (WS) of INH in all wells of row $\mathrm{C}$ from MCT-1

- Dispense $100 \mu$ l of WS of RIF in all wells of row D from MCT-2.

- Add $100 \mu \mathrm{l}$ remaining MC to rest of all the wells of row $\mathrm{A}$ and $\mathrm{B}$ to make final volume of $1 \mathrm{ml}$ in each well.

- Close the plate with its lid and seal it with parafilm from all sides or zip lock bag.

- Incubate at $37^{\circ} \mathrm{C}$. (Note: If more than five samples or cultures are being tested use another plate. It is advisable not to test samples/cultures on the same plate on which QC strains are being run to avoid cross-contamination.)

\section{For quality control}

For each batch 1 set of separate QC $\left(1 \mathrm{H}_{37} \mathrm{Rv}\right.$ and $\left.1 \mathrm{MDR}\right)$ plate is run.

- Take a 24 well plate

- Mark the wells on plate: $\mathrm{H}_{37} \mathrm{Rv}, \mathrm{MC}, \mathrm{MDR}, \mathrm{INH}$ and RIF, as shown in Figure 5

- Dispense $900 \mu \mathrm{l}$ of suspension of $\mathrm{H}_{37} \mathrm{Rv}$ in all four wells of column 1

- Dispense $900 \mu \mathrm{l}$ of suspension of MDR in all four wells of column 3

- Dispense $900 \mu \mathrm{l}$ of $\mathrm{MC}$ in all 4 wells of column 2

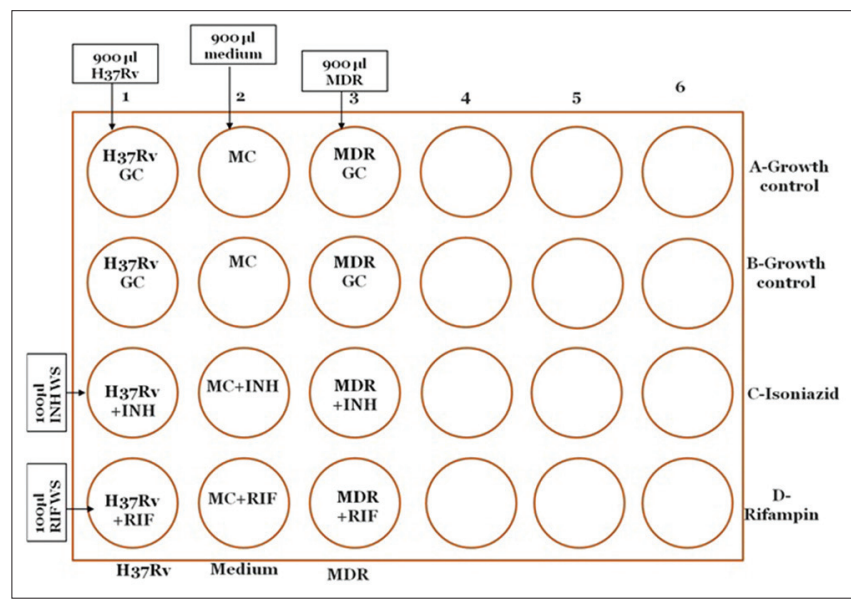

Figure 5: Setting up of microscopic observation drug susceptibility assay plate for quality control strains

Journal of Laboratory Physicians / Jul-Dec 2012 / Vol-4 / Issue-2 
- Dispense $100 \mu \mathrm{l}$ of WS of INH in wells $1-3$ of row C from MCT-1

- Dispense $100 \mu \mathrm{l}$ of WS of RIF in wells 1-3 of row D from MCT-2

- Add $100 \mu \mathrm{l}$ remaining MC to rest of all the wells of row $\mathrm{A}$ and $\mathrm{B}$ to make final volume of $1 \mathrm{ml}$ in each well

- Close the plate with its lid and seal it with parafilm from all sides or place in a zip lock bag

- Incubate at $37^{\circ} \mathrm{C}$

Plate reading

A positive result is defined as two or more colony forming units ( $>2 \mathrm{cfu}$ ) in each of the two drug-free wells.

Positive control: If positive controls do not grow in the expected pattern, the results of samples plated on the same day are not valid.

Negative control: If any mycobacterial colonies are observed in any media control well, it indicates cross-contamination, results of samples plated on the same day are not valid.

\section{Plate reading of GC/drug-free wells}

- $\quad$ Start examining drug-free wells on day 5.

- Early mycobacterial growth looks like small curved commas or spirals (days 5-9).

- Confirm the growth as M. tuberculosis using MPT-64, PNB or any other standard method. Reading should be followed only if the growth is MTB (not required in case of indirect MODS).

- Colony formation usually progresses to cords, and later more irregular tangled growth.

- If two or more colonies ( $>2 \mathrm{cfu}$ ) are detected in each of the two wells, the result is positive.

- If results are negative on day 5, continue reading drug-free wells daily (or on alternate days according to laboratory workload) until $>2 \mathrm{cfu}$ are observed in each of the two wells.

- When a positive result is observed, read the INH and RIF containing wells on the same day.

- If no growth is observed by day 15 , repeat reading on day 18 and day 21. If results are still negative on day 21 the final result is negative.

- If only $1 \mathrm{cfu}$ appears in either drug-free well, or in both, the result is "indeterminate". [ Table 5]

Before final results can be considered valid, the QC and $\mathrm{MC}$ wells must be examined and interpreted.

- For initial readings, examine wells with the $\times 10$

\begin{tabular}{|c|c|c|c|}
\hline Well & Observation & $\begin{array}{l}\text { Interpretation } \\
\text { of well findings }\end{array}$ & $\begin{array}{l}\text { Overall culture } \\
\text { interpretation }\end{array}$ \\
\hline A & No growth & Negative & \multirow{2}{*}{$\begin{array}{l}\text { No growth in both/ } \\
\text { either well }\end{array}$} \\
\hline B & No growth & Negative & \\
\hline A & $\geq 2 \mathrm{cfu}$ & Positive & \multirow[t]{2}{*}{ Intermediate } \\
\hline B & No growth & Negative & \\
\hline A & $1 \mathrm{cfu}$ & Intermediate & \multirow[t]{2}{*}{ Intermediate } \\
\hline B & $1 \mathrm{cfu}$ & Intermediate & \\
\hline A & $\geq 2 \mathrm{cfu}$ & Positive & \multirow[t]{2}{*}{ Intermediate } \\
\hline B & $1 \mathrm{cfu}$ & Intermediate & \\
\hline A & $\geq 2 \mathrm{cfu}$ & Positive & \multirow[t]{2}{*}{ Positive } \\
\hline B & $\geq 2 \mathrm{cfu}$ & Positive & \\
\hline A & Fungal/bacterial growth & Contamination & \multirow{2}{*}{$\begin{array}{l}\text { Contamination in } \\
\text { both/either well }\end{array}$} \\
\hline B & Fungal/bacterial growth & Contamination & \\
\hline
\end{tabular}

microscope objective to search for early colony forms ( $\times 100$ final magnification). For subsequent readings, use the $\times 4$ objective ( $\times 40$ final magnification) to examine the entire contents of each well.

- The culture medium does not become cloudy with growth of M. tuberculosis.

- Growth in only one well, or less than 2 cfu in each of the two wells, should be considered an indeterminate result, and should prompt a request for a repeat sample and a search for evidence of cross-contamination.

- Intervals between readings can be flexible to suit laboratory workload and schedule. (Notes: More frequent readings yield faster results.)

\section{Reading of drug wells}

- On the same day that both drug-free wells have definite mycobacterial growth of $>2 \mathrm{cfu}$, examine the INH- and RIF-containing wells.

- If there is any growth of $>2$ cfu in a drug-containing well, the sample is resistant to that drug (at the concentration present); no growth means the sample is sensitive to the drug.

- If there is positive growth in both INH- and RIF-containing wells, the sample is MDR.

- Drug-containing wells should NOT be re-examined if the reading of drug-free well is identified as negative. (Notes: Growth may be less florid in the drug-containing well but the presence of $\geq 2 \mathrm{cfu}$ indicates resistance (this is not a proportions-type test).)

- Only very rarely is a single cfu detected in drug-containing wells (read at the correct time point), however if this is encountered the interpretation is indeterminate.

- Growth in drug-containing wells should only be considered as indicating resistance if drug-free wells for the same sample have also shown growth [Table 6]. 


\begin{tabular}{|c|c|c|c|}
\hline Well & Observation & $\begin{array}{l}\text { Interpretation } \\
\text { of well findings }\end{array}$ & $\begin{array}{l}\text { Overall drug } \\
\text { susceptibility } \\
\text { interpretation }\end{array}$ \\
\hline c & No growth & Susceptible & \multirow{2}{*}{ Susceptible } \\
\hline D & No growth & Susceptible & \\
\hline c & $\geq 2 \mathrm{cfu}$ & Resistant & \multirow{2}{*}{ Mono-resistant } \\
\hline D & No growth & Susceptible & \\
\hline C & $1 \mathrm{cfu}$ & Intermediate & \multirow{2}{*}{ Intermediate } \\
\hline D & $1 \mathrm{cfu}$ & Intermediate & \\
\hline C & $\geq 2 \mathrm{cfu}$ & Resistant & \multirow{2}{*}{ Mono-resistant } \\
\hline D & $1 \mathrm{cfu}$ & Intermediate & \\
\hline C & $\geq 2 \mathrm{cfu}$ & Resistant & \multirow{2}{*}{ MDR } \\
\hline D & $\geq 2 \mathrm{cfu}$ & Resistant & \\
\hline c & Fungal/bacterial growth & Contamination & \multirow{2}{*}{$\begin{array}{l}\text { Contamination } \\
\text { in both/either } \\
\text { well-contamination }\end{array}$} \\
\hline D & Fungal/bacterial growth & Contamination & \\
\hline
\end{tabular}

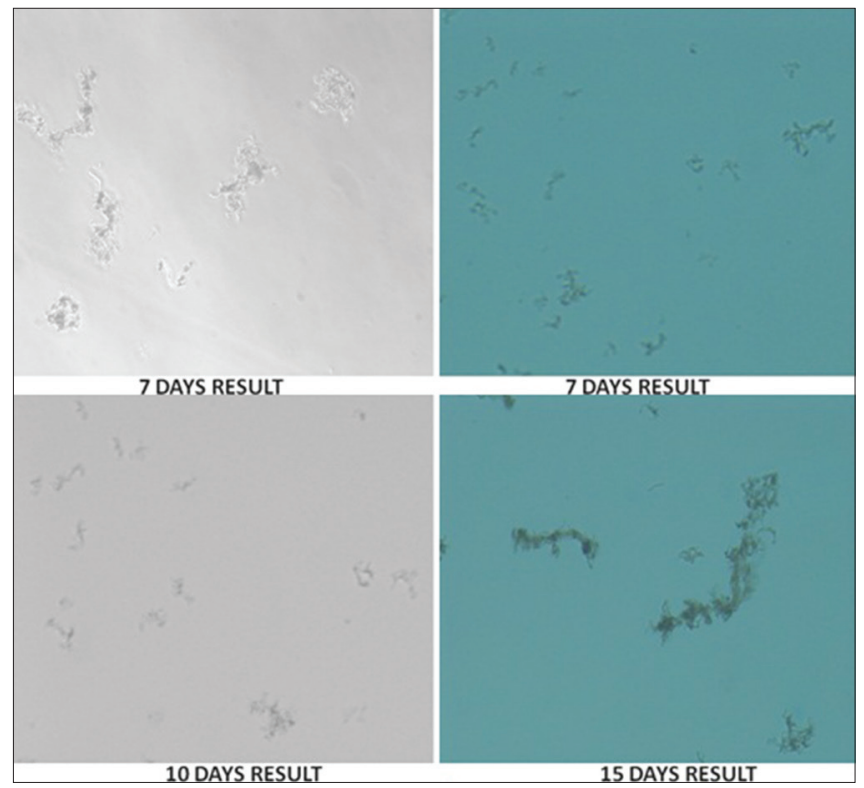

Figure 6: Demonstration of microscopic observation drug susceptibility assay results on different days of incubation, under different light settings. 7 days: Growth of mycobacterial cords on day 7, 10 days: Growth of mycobacterial cords on day 10. 15 days: Growth of mycobacterial cords on day 15

\section{Reading of medium control}

- All four wells in of MC should have no growth.

- If any mycobacterial colonies are observed in any well, there has been cross-contamination. The entire plate should be discarded.

- A search for potential sources of cross-contamination should occur and if the source is identified appropriate, remedial action should be taken.

\section{Reading of quality control wells}

\section{i. Drug-free wells}

- All drug-free wells should have positive mycobacterial growth ( $>2 \mathrm{cfu})$.

- Absence of growth in all drug-free wells suggests that the medium does not support growth sample results are not valid. All samples plated out on the same day should be reprocessed with a new batch of medium.

- If only one of the two positive control strains grows in drug-free wells, the strain that did not grow may not be viable. A fresh strain suspension should be used with re-testing.

\section{ii. Drug-containing wells}

- The drug-susceptible control strain should not grow in either of the drug-containing wells. Growth indicates incorrect (low) antibiotic concentrations or inadequate INH and/or RIF activity.

- The drug-resistant control strain (1 MDR strain, or 2 mono-resistant strains) should grow in the drug-containing wells. Absence of growth indicates that the final INH and/or RIF concentrations are too high. (Notes: Absence of control strain growth in all drug-free wells may also indicate strain non-viability. Consider use of fresh control strain preparations for re-testing.)

- Reduced drug activity may be due to incorrect concentrations, or reduced potency related to improper handling or storage of original, undiluted, drug or drug stock solution.

\section{MODS results on different days}

For interpretation of results, refer to Figure 6.

Plate disposal

- Keep all plates sealed inside their original zip lock plastic bags and seal in an autoclave bag.

- Autoclave at $121^{\circ} \mathrm{C}$ for $30 \mathrm{~min}$.

- Discard the sealed sterilized bags in the site designated for this purpose.

\section{Quality assurance}

The MODS method described in this SOP includes sterility checks for stock solutions and medium. The positive internal controls test medium and antibiotic solution function; the negative internal controls test for cross-contamination.

\section{ACKNOWLEDGMENTS}

The authors would like to thank Dr. Alessandra Varga of Journal of Laboratory Physicians / Jul-Dec 2012 / Vol-4 / Issue-2 
FIND for her administrative support to this project, to Dr. David Moore for his technical inputs in the preparation and finalization of this SOP and all core members of the New Diagnostic Working Group (NDWG) for approving this project.

\section{FURTHER READING}

1. Caviedes L, Moore DA. Introducing MODS: A low-cost, low-tech tool for high-performance detection of tuberculosis and multidrug resistant tuberculosis. Indian J Med Microbiol 2007;25:87-8.

2. Kent PT, Kubica GP. Public Health Mycobacteriology: A Guide for the Level III Laboratory. Washington, DC, Centres for Disease Control and Prevention, Atlanta US Government Printing Office; 1985. p. 207.

3. Coronel J, Roper M, Caviedes L, Moore D. MODS. A User Guide. Microscopic-Observation Drug-Susceptibility Assay, 2008. Available from:
http://www.modsperu.org/MODS_user_guidepdf. V12.213012012. [Last Accessed on 2012 Feb 28].

4. Moore DA. Future prospects for the MODS assay in multidrug-resistant tuberculosis diagnosis. Future Microbiol 2007;2:97-101.

5. World Health Organization. Noncommercial culture and drug susceptibility testing methods for screening of patients at risk of multi drug resistant tuberculosis: Policy statement; July, 2010. Available from: http://www. who.int/tb/dots/laboratory/whopolicy_noncommercialculture_and_ dstmethods_july10.pdf. [Last accessed on 2012 Nov 10].

How to cite this article: Singh S, Kumar P, Sharma S, Mumbowa F, Martin A, Durier N. Rapid Identification and Drug Susceptibility Testing of Mycobacterium tuberculosis: Standard Operating Procedure for NonCommercial Assays: Part 1: Microscopic Observation Drug Susceptibility Assay v2.4.12. J Lab Physicians 2012;4:101-11.

Source of Support: Culture and drug susceptibility testing subgroup, Stop-TB Partnership, WHO \& FIND, Geneva, Switzerland. Conflict of Interest: None declared. 